\title{
Mapping Long-Term Changes in Mangrove Species Composition and Distribution in the Sundarbans
}

\author{
Manoj Kumer Ghosh ${ }^{1, *}$, Lalit Kumar ${ }^{1}$ and Chandan Roy ${ }^{2}$ \\ 1 Ecosystem Management, School of Environmental and Rural Science, University of New England, \\ Armidale 2351, NSW, Australia; 1kumar@une.edu.au \\ 2 Geography and Environmental Studies, University of Rajshahi, Rajshahi 6205, Bangladesh; \\ chandanroy@gmail.com \\ * Correspondence: mghosh@myune.edu.au; Tel.: +61-2677-35239
}

Academic Editors: Christian Ginzler and Timothy A. Martin

Received: 27 September 2016; Accepted: 29 November 2016; Published: 3 December 2016

\begin{abstract}
The Sundarbans mangrove forest is an important resource for the people of the Ganges Delta. It plays an important role in the local as well as global ecosystem by absorbing carbon dioxide and other pollutants from air and water, offering protection to millions of people in the Ganges Delta against cyclone and water surges, stabilizing the shore line, trapping sediment and nutrients, purifying water, and providing services for human beings, such as fuel wood, medicine, food, and construction materials. However, this mangrove ecosystem is under threat, mainly due to climate change and anthropogenic factors. Anthropogenic and climate change-induced degradation, such as over-exploitation of timber and pollution, sea level rise, coastal erosion, increasing salinity, effects of increasing number of cyclones and higher levels of storm surges function as recurrent threats to mangroves in the Sundarbans. In this situation, regular and detailed information on mangrove species composition, their spatial distribution and the changes taking place over time is very important for a thorough understanding of mangrove biodiversity, and this information can also lead to the adoption of management practices designed for the maximum sustainable yield of the Sundarbans forest resources. We employed a maximum likelihood classifier technique to classify images recorded by the Landsat satellite series and used post classification comparison techniques to detect changes at the species level. The image classification resulted in overall accuracies of $72 \%$, $83 \%, 79 \%$ and $89 \%$ for the images of 1977, 1989, 2000 and 2015, respectively. We identified five major mangrove species and detected changes over the 38-year (1977-2015) study period. During this period, both Heritiera fomes and Excoecaria agallocha decreased by $9.9 \%$, while Ceriops decandra, Sonneratia apelatala, and Xylocarpus mekongensis increased by $12.9 \%, 380.4 \%$ and $57.3 \%$, respectively.
\end{abstract}

Keywords: mangroves; Sundarbans; remote sensing; image classification; change detection; Landsat

\section{Introduction}

The appraised global coverage of mangrove forest is $137,760 \mathrm{~km}^{2}$ [1,2]; this equates to $0.1 \%$ of the earth's surface [3]. These mangroves are declining worldwide at an alarming rate [4-7]. Globally, $36,000 \mathrm{~km}^{2}$ of mangroves have been lost since 1980, primarily due to conversion to agriculture and aquaculture, urbanization, and timber extraction [8]. The Sundarbans, the largest contiguous mangrove forest in the world $[9,10]$, is considered as a site of national and international importance for the conservation of biodiversity [11,12]. The Sundarbans covers an area of approximately $10,000 \mathrm{~km}^{2}$ and lies in the territory of Bangladesh and India $[9,13]$. This forest has enormous ecological and economic importance at local, national and global scales [11]. The Sundarbans plays an important role in the local as well as global ecosystem by absorbing carbon dioxide and other pollutants from air and water [14], offering protection to millions of people in the Ganges Delta against cyclone and 
water surges [15], stabilizing the shore line, trapping sediment and nutrients, purifying water, etc. [16]. According to Donato et al. [17] and Rodda et al. [18], mangroves are the most carbon-rich forests in the tropics. Despite their small spatial extent, mangroves are considered as an important resource around the world due to their ability to store and sequester carbon, compared to many freshwater wetlands [2]. The Sundarbans absorbs 469.2 to 569.2 Mega grams of carbon per hectare [17,19]. The total economic value of mangroves has been estimated between USD 200,000 and 900,000 per ha/year [20], which is estimated through the cost of the products and services they provide. The total economic value of mangroves in Malaysia, Mexico and Sri Lanka were USD 61,357, USD 2,772 and USD 12,229 per hectare per year, respectively [21-23]. In 1997, the mangroves of Sundarbans, Bangladesh, were valued at USD 631 per hectare per year considering only the ecological services [24]. A complex and varied vegetation structure enhances the growth of a diverse range of plants and animals in the complex ecosystem of the Sundarbans, and it makes this ecosystem a unique one in the world [16,25]. This forest is an example of an endangered ecological system that is highly populated and both fragile and economically valuable [26]. More than 2.5 million people live in the villages surrounding the Sundarbans, and this biodiversity hotspot has great socioeconomic value for the livelihood of the local people [15]. The forest provides livelihood for over 300,000 people working within a range of seasonal areas such as wood cutters, fishermen, honey collectors, etc. [3,15]. Apparently, like other mangrove forests of the world, this forest is under pressure due to a number of factors; historical and current, natural and anthropogenic, including global climate change [26,27], and these factors could have a severe impact on the biodiversity of the forest in terms of sustainability in the long run. This mangrove ecosystem is under threat mainly due to climate change and anthropogenic degradation [27]. Anthropogenic and climate change-induced degradation, such as over-exploitation of timber and pollution, coastal erosion, increasing salinity, effects of increasing number of cyclones and higher levels of storm surges, remains a recurrent problem in the Sundarbans [3], and recent changes in the intensity and location of these degradations have not been regularly assessed due to a lack of a proper and effective monitoring system.

Mapping and monitoring of the Sundarbans mangrove forest has become an urgent need due to its enormous ecological and economic importance. In the Sundarbans, periodic forest inventories have taken place approximately every 15 to 20 years [15] for collecting detailed information on the forest resources, but the focus has remained on timber yield [28]. The last detailed inventory was undertaken 30 years ago by the Department for International Development of the United Kingdom (formerly, Overseas Development Administration) in Bangladesh [15,29] and, based on this inventory, a mangrove cover map at a species level was produced. The preparation of this map was very strenuous and time consuming as it took around 5 years (1981-1985) using aerial photographs and ground surveys [30]. Remote sensing, on the other hand, is comparatively very effective in terms of cost, time and accuracy $[7,31]$ and therefore is efficient in monitoring mangrove species dynamics because of its synoptic and repeated coverage and historical data [32]. For mapping and change detection purposes, a number of studies conducted in the Sundarbans have applied remote sensing tools (for example [15,33-38]); however, most of the studies have kept their focus only on determining spatial change. Giri and co-authors [39] identified mangrove composition and their changes at the species level in the Sundarbans, but this was only for the Indian Territory. Therefore, plant species and their distribution and dynamics remain unrecorded for the entire Sundarbans mangrove forest comprising both countries. Moreover, due to the unavailability of a detailed species level map and a continuous monitoring system, sustainable management planners, other relevant stakeholders and researchers are not well informed about the changes that are taking place as a result of changing climate and anthropogenic degradation. Considering the importance of the Sundarbans, accurate and up-to-date information on the composition, distribution and the dynamics of the mangrove species is an essential requisite [15] to avoid over-exploitation of resources and to ensure their sustainable management. Therefore, detailed species-level mapping and regular monitoring of their dynamics in the Sundarbans mangrove forest is urgently needed for ensuring sustainability. Detailed information 
on the mangrove species and their composition and dynamics can lead to adoption of management practices designed for maximum sustainable yield. This could be a crucial factor in preserving what remains of the Sundarbans. Emphasis on preparing a database related to mangrove species composition and dynamics of the Sundarbans mangrove forest for managing the entire ecosystem may help to sustain this valuable resource well into the future.

In this paper, we examine the mangrove species composition in the Sundarbans for four different periods to understand the species composition dynamics of this forest over the last 38 years using freely available multi-temporal Landsat imagery and conventional classification (maximum likelihood classifier) and change detection techniques. More importantly, we investigate the dynamic nature of mangrove species in the Sundarbans. Moreover, this study describes some of the driving forces (e.g., coastal dynamics, anthropogenic, natural forces) that influence the mangrove cover dynamics at a species level in the Sundarbans. We measure the mangrove species dynamics of the Sundarbans at four intervals between 1977 and 2015 (1977-1989, 1989-2000, 2000-2015 and 1977-2015). It is anticipated that successful mangrove cover mapping at the species level with acceptable accuracy and detection of species level dynamics using Landsat satellite data will provide an information base and predictive route, especially under climate change scenarios and different anthropogenic influences, for sustainable management planning and maintaining the sustainability of the Sundarbans mangrove forest. This will also encourage other researchers and relevant stakeholders to develop a proper and continuous monitoring system for the entire Sundarbans mangrove forest in a simple, time saving, efficient and cost effective way. This will also open up the avenue of such applicability for other developing countries having similar issues.

\section{Materials and Methods}

\subsection{Study Area}

The present study was conducted in the Sundarbans mangrove forest, the largest single tract of mangrove ecosystem in the world [36,40,41]. This forest is located on the Ganges Delta created by the confluence of three mighty river systems, Ganges, Brahmaputra and Meghna, at the northern limit of the Bay of Bengal $[27,42]$ and it extends between approximately $21^{\circ} 32^{\prime}$ to $22^{\circ} 40^{\prime} \mathrm{N}$ latitude and $88^{\circ} 05^{\prime}$ to $89^{\circ} 51^{\prime}$ E longitude (Figure 1). The Sundarbans is crisscrossed by a complex network of river channels and comprises a number of mudflats and small islands. These small islands and mudflats are created as a result of the sedimentation process that is influenced by the river system intersecting this forest $[9,42]$. This forest region is characterized by a tropical climate with four main seasons that include pre-monsoon (March to May), monsoon (June to September), post-monsoon (October-November) and dry winter (December to February). Rainfall and temperature fluctuates between $1600 \mathrm{~mm}$ and $2000 \mathrm{~mm}$ and $11^{\circ} \mathrm{C}$ and $37^{\circ} \mathrm{C}$, respectively in this region, while elevation varies between 0.9 and $2.11 \mathrm{~m}$ above sea level $[9,36]$. The Sundarbans is considered as a safe habitat for a wide range of plants and animals, including 27 mangrove species, 40 mammal species, 35 reptile species, and 260 species of birds [15]. Floristically, mangrove species of the Sundarbans belong to the Indo-Andaman mangrove province within the species-rich Indo-West Pacific group $[9,43]$. 


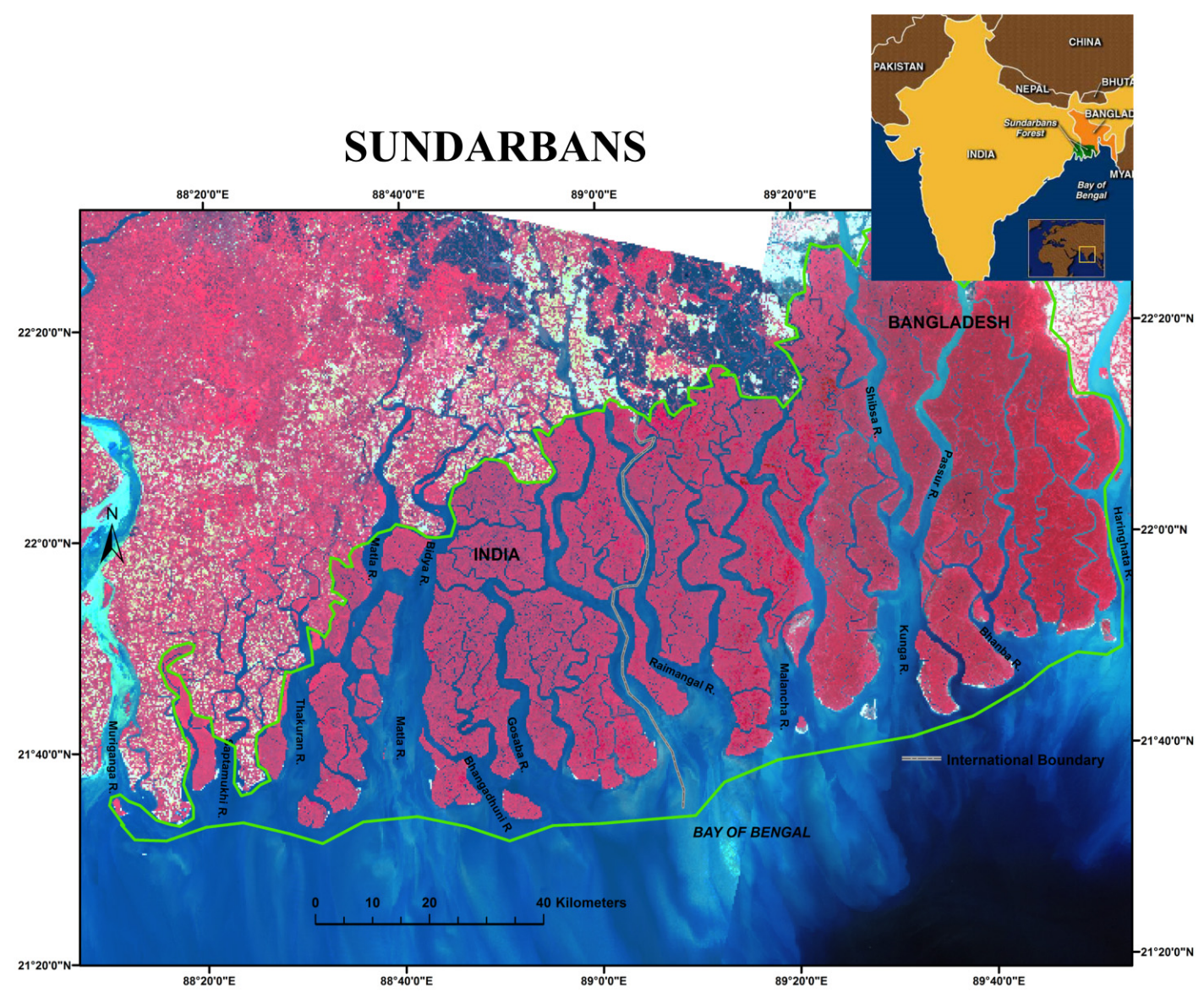

Figure 1. Location of the study area (False color composite image).

\subsection{Images Used}

In this study, satellite images of four time periods were used to quantify the dynamics of mangrove species composition of the Sundarbans: (a) the Landsat Multispectral Scanner (MSS) (57 m spatial resolution) acquired in February 1977; (b) the Landsat Thematic Mapper (TM) (28.5 spatial resolution) acquired in February 1989; (c) the Landsat Enhanced Thematic Mapper (ETM+) (28.5 m spatial resolution) acquired in February 2000; and (d) the Landsat Operational Land Imager (OLI) (30 m spatial resolution) acquired in February 2015 (Table 1). The Landsat MSS has four spectral bands while TM and ETM+ have seven and OLI has eleven spectral bands. All the Landsat images covering the entire Sundarbans were acquired from the US Geological Survey (USGS) Center for Earth Resources Observation and Science (EROS) website (www.glovis.usgs.gov).

Table 1. Information of Landsat data used to map mangrove cover at the species level in the Sundarbans.

\begin{tabular}{cccc}
\hline Sensor & Resolution (in Meter) & Path/Row & Date \\
\hline MSS & 57 & $147-148 / 45$ & 1 February 1977 \\
TM & 28.5 & $137-138 / 45$ & 5 February 1989 \\
ETM+ & 28.5 & $137-138 / 45$ & 28 February 2000 \\
OLI & 30 & $137-138 / 45$ & 4 February 2015 \\
\hline
\end{tabular}

\subsection{Image Preprocessing}

For all images (MSS, TM, ETM+ and OLI), radiometric correction was carried out to remove the influence of the atmosphere. Atmospheric interference caused by haze, dust, smoke, etc. was 
corrected using the dark-object subtraction method [44]. Radiometric correction was performed using sun elevation and sun azimuth data extracted from the images' header file [45]. To make the images comparable, all were converted from digital number values to top-of-atmosphere reflectance as per the suggestion of Chander and Markham [46], and a relative radiometric normalization was performed by normalizing the variation in solar illumination and atmospheric conditions [47-49]. Registration of all the images was done using 51 ground control points (GCPs) with a root mean square error (RMSE) of 0.003957 pixels, and then the images were resampled to a $30 \mathrm{~m}$ pixel size using the nearest neighbor resampling method. The Sundarbans is covered by two frames (Path 137 Row 45 and Path 138 Row 45 for TM, ETM+ and OLI, and Path 147 Row 45 and Path 148 Row 45 for MSS) of Landsat satellite images. To consider the entire Sundarbans as a study site, all of the individual images were mosaicked. Using an on-screen digitization process, only the mangrove areas were extracted for further study and afterwards, waterbodies were masked out from the images so that the result would not be impacted by the effect of tide and different turbidity water that formed multiple classes in the classified image. The entire image-processing task was carried out using ENVI 5.1 software (Exelis Visual Information Solutions, Inc., Boulder, UT, USA).

\subsection{Image Classification}

In this study, the supervised maximum likelihood classification algorithm (MLC) was used to classify and extract the mangrove species composition of the Sundarbans due to its well-developed theoretical base, simplicity and ease of use [50]. The MLC algorithm is one of the most well-known parametric classifiers used for supervised classification. This MLC algorithm computes the weighted distance or likelihood of an unknown measurement vector that belongs to one of the known classes, based on the Bayesian equation. The unknown measurement vector is assigned to the class based on the highest probability of fit. Consideration of a variance-covariance matrix within the class distributions is considered one of the advantages of this algorithm. This technique is extensively used in remote sensing where a pixel with the maximum likelihood is classified in the corresponding class [39]. For training and validation sampling, fieldwork and published maps were used. Fieldwork for training and validation sampling for the 2015 imagery was completed in February-March 2016, and Landsat image data, a printed image of Google Earth and a reference map of the Sundarbans (published by Bangladesh Forest Department) were used as guides. Fieldwork was conducted only in the Bangladesh territory of the Sundarbans mangrove forest. A species-level map of the Sundarbans mangrove forest that was mapped only for the Bangladesh territory by the Bangladesh Forest Department in 1985 was used as reference data for training and validation sampling for the 1989 image. Due to the unavailability of corresponding reference data for the 1977 and 2000 images, training and validation samples that were developed for the 1989 image classification and accuracy evaluation were also used for the classification and accuracy evaluation for the 1977 and 2000 images. To use these samples, a process called signature extension as suggested by Foody [51,52] was undertaken as this allows us to use samples for unchanged areas for such purposes. In several studies in the recent past, this method has been used successfully [53-55]. To do this, additional processing was undertaken to include sample points that had not changed during the periods 1989-1977 and 1989-2000. An image differencing technique was used to generate difference images for the above images with respect to the 1989 image (e.g., 1989-2000 and 1989-1977). At first, the NDVI of each study year was computed, and by subtracting each year's NDVI from the 1989 NDVI, a difference image was generated. Due to the capabilities of reflecting both vegetation and non-vegetation areas, an NDVI image was used for this purpose. Afterwards, to separate the change/no-change areas, thresholds of \pm 1 standard deviation (SD) $[47,53]$ were used. Pixels that were not changed during the above-mentioned periods usually clustered about the mean of the difference histogram distribution, whereas changed pixels were found within the tails. In comparison to the change images, all the training and validation samples developed for the 1989 image were assessed, and samples that fell in areas greater than \pm 1 SD from the mean were discarded. The remaining samples were assumed to have not changed over the years and were used 
as validation data for classification and accuracy evaluation, as supported by Sinha and Kumar [56]. All of the images were limited to only mangrove areas, thus training and validation samples were only developed for different mangrove species. Considering the true representation of class, accessibility and size of class, training samples between 51 and 141 for each species were randomly selected, stratified by land cover class. The numbers of training samples varied for different mangrove species based on class abundance and distribution in the study area. In addition, care was taken so that the samples were well distributed in the study area and also fulfilled the minimum number required for valid accuracy evaluation process [57]. Altogether 414, 429, 549 and 471 training samples were assessed throughout the study area to represent identified mangrove species and their natural variance for the 2015, 2000, 1989 and 1977 images, respectively.

On the basis of spectral signature-based satellite image classification, identification and distribution of mangrove species were analyzed in this study. A handheld GPS was used to collect the training sets for different mangrove species from the field, and collected GPS locations of various mangrove species were overlaid on satellite images from 2015 to extract the spectral signature. To classify the imagery of 1977, 1989 and 2000, training sites were developed from the reference map, and spectral signatures were generated for different mangrove species. Afterwards, extracted spectral signatures were used for image classification and identification of mangrove species. In addition to supplementary information obtained from various sources, the author's prior knowledge was also used to document characteristics of different mangrove species, as supported by Kumar and Ghosh [58]. There are 27 mangrove species in the Sundarbans [15], but many of these are present in small quantities, spread over wide areas in small patches and thus unable to be detected using medium-resolution satellite data. Hence, we mapped the five major mangrove species of the Sundarbans in this study, named Heritiera fomes, Excoecaria agallocha, Ceriops decandra, Sonneratia apelatala and Xylocarpus mekongensis. The remaining species were classified under the major five mangrove species on the basis of dominance. The spectral profiles of five species, H. fomes, E. agallocha, C. decandra, S. apelatala and X. mekongensis, are shown in Figure 2. The five major species were selected based on the information obtained from previously published literature $[15,29,35,59]$ and species-level maps of the Sundarbans. Figure 3 shows the workflow for image processing and change detection.

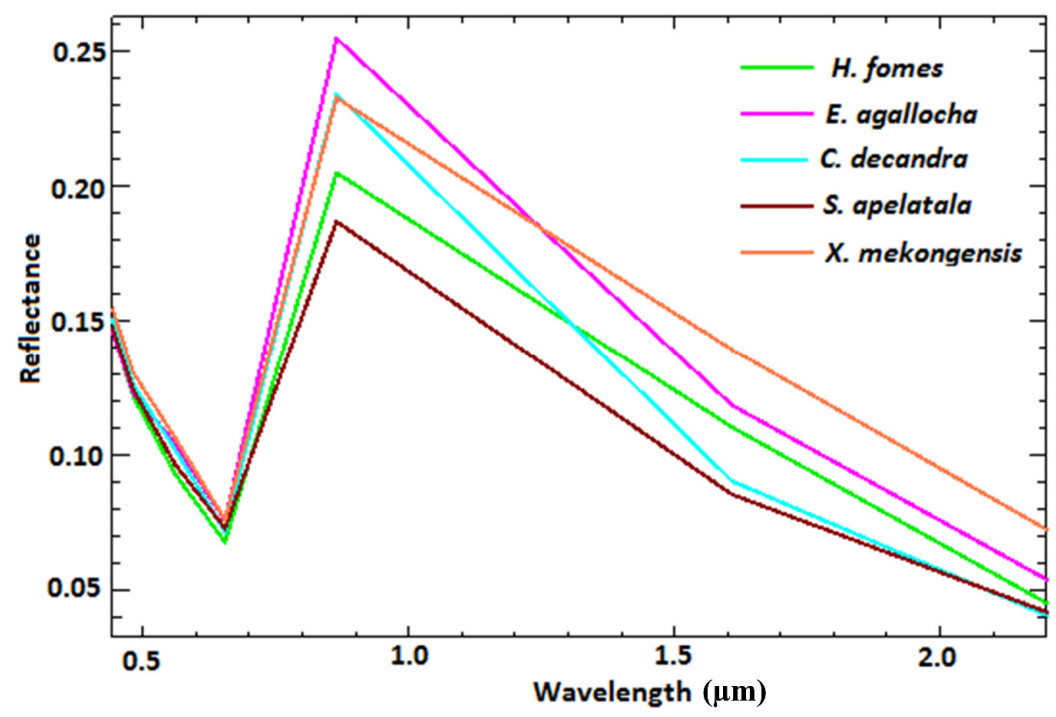

Figure 2. Spectral profile of various mangrove species. All five mangrove species show similar reflectance patterns in the lower wavelengths of the spectrum. In contrast, reflectance patterns are different in the higher wavelengths of the spectrum. To be more specific, the spectral profiles of the five mangrove species follow each other between the wavelengths of 0.5 and $0.7 \mu \mathrm{m}$. The reflectance patterns become different after $0.7 \mu \mathrm{m}$, and this difference is maintained for the remaining portion of the spectrum. 


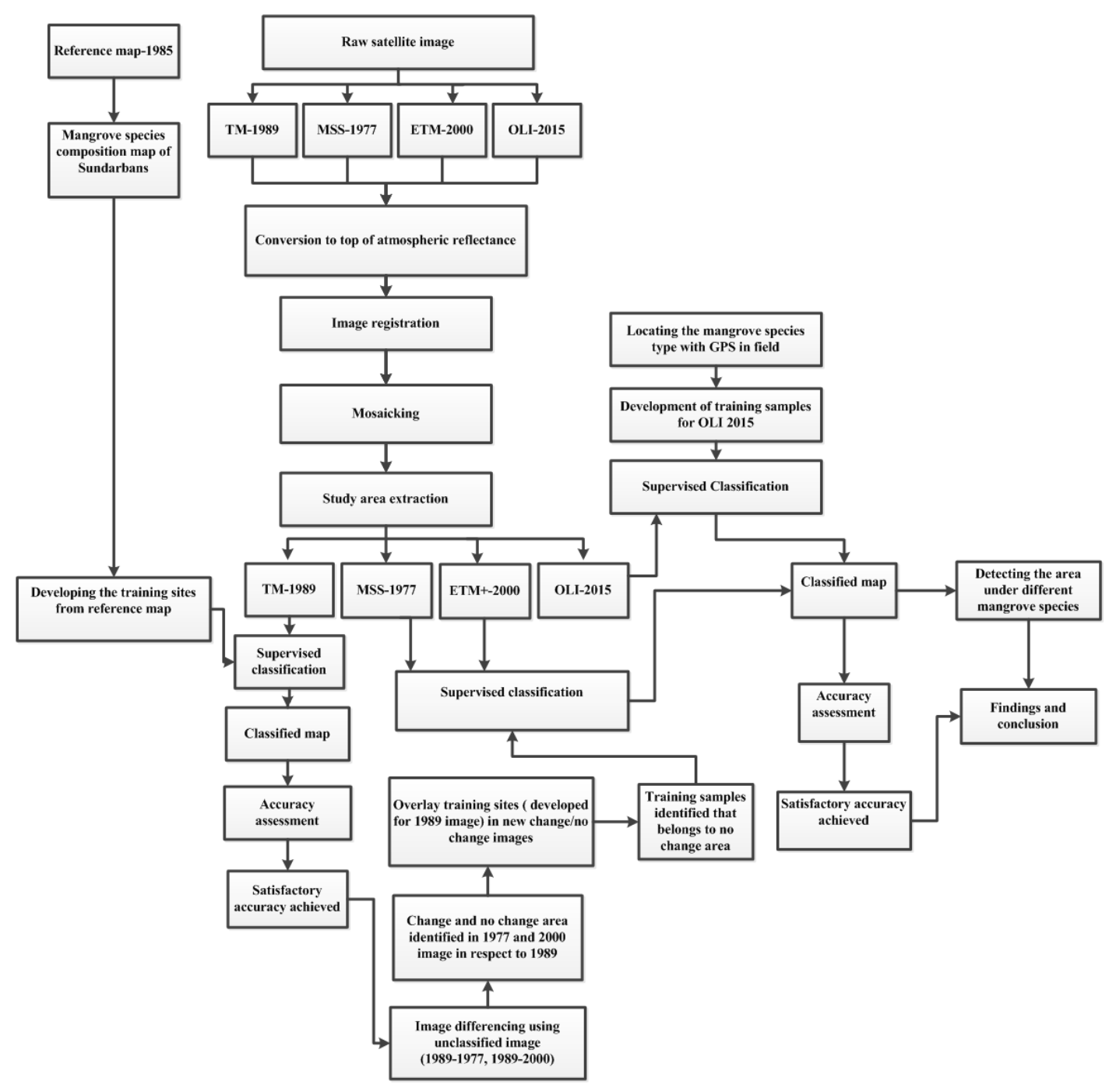

Figure 3. Work flowchart of research.

\subsection{Change Detection Analysis}

Post classification comparison techniques were used to detect changes in species composition from the four imagery dates. This approach provides "from-to" change information and is considered the most common change detection method. Changes in mangrove species composition were mapped by subtracting the classified maps between four periods: 1977-1989, 1989-2000, 2000-2015 and 1977-2015. A change matrix was also developed to understand the dimension of the change. To identify the driving forces responsible for the change, change areas were visually interpreted. For better understanding of driving forces and their impacts on species dynamics, published documents were also used.

\subsection{Classification Accuracy}

Validation of classification is an integral part of any image classification process [56]. In this research, an accuracy assessment method described by Congalton and co-authors $[57,60,61]$ was used to estimate the accuracy of the image classification. 


\section{Results}

Spatiotemporal distributions of different mangrove species of the Sundarbans are shown for the years 1977, 1989, 2000 and 2015 in Figure 4, and statistics regarding species composition are shown in Table 2. Details of the detected change in the mangrove species composition in the study area are summarized in Table 3, and the change matrix is shown in Table 4.

The results indicate that during the study period, both H. fomes and E. agallocha decreased by $9.9 \%$, while C. decandra, X. mekongensis and S. apelatala increased by $12.9 \%, 57.3 \%$ and $380.4 \%$, respectively. However, the rate of change was not uniform during the study period between 1977 and 1989, 1989 and 2000 and 2000 and 2015. From 1977 to 1989, H. fomes, E. agallocha and X. mekongensis decreased by $1.7 \%, 2.5 \%$ and $36 \%$, respectively, while $C$. decandra and S. apelatala increased by $4.3 \%$ and $159.4 \%$, respectively, and from 1989 to 2000, H. fomes and E. agallocha decreased by $1.5 \%$ and $8.8 \%$, respectively, whereas $C$. decandra, X. mekongensis and S. apelatala increased by $1.3 \%, 126.1 \%$ and $47.2 \%$, respectively. Between 2000 and 2015, only the area under H. fomes decreased by 6.9\%. In contrast, E. agallocha, C. decandra, X. mekongensis and S. apelatala increased by $1.3 \%, 6.9 \%, 8.7 \%$ and $25.8 \%$, respectively. The spatiotemporal dynamics of the mangrove species are shown in Figure 5.

Four confusion matrices were created to compute overall accuracy, users' accuracy, producers' accuracy and the kappa coefficient. The image classification resulted in overall accuracies of $72 \%, 83 \%$, $79 \%$ and $89 \%$ and a kappa index of $0.64,0.74,0.73$ and 0.87 for the images of 1977, 1989, 2000 and 2015 , respectively.

Table 2. Mangrove species composition pattern analysis of the Sundarbans (1977-2015).

\begin{tabular}{ccccccccc}
\hline \multirow{2}{*}{$\begin{array}{c}\text { Mangrove } \\
\text { Species }\end{array}$} & \multicolumn{4}{c}{ Area in Hectares } & \multicolumn{4}{c}{ Area in Percentage (\%) } \\
\cline { 2 - 8 } & $\mathbf{1 9 7 7}$ & $\mathbf{1 9 8 9}$ & $\mathbf{2 0 0 0}$ & $\mathbf{2 0 1 5}$ & $\mathbf{1 9 7 7}$ & $\mathbf{1 9 8 9}$ & $\mathbf{2 0 0 0}$ & $\mathbf{2 0 1 5}$ \\
\hline H. fomes & 221,886 & 218,051 & 214,679 & 199,857 & 36.8 & 36.1 & 36.1 & 33.4 \\
E. agallocha & 200,662 & 195,692 & 178,425 & 180,742 & 33.3 & 32.4 & 30.0 & 30.2 \\
C. decandra & 171,590 & 178,972 & 181,238 & 193,698 & 28.5 & 29.6 & 30.5 & 32.4 \\
X. mekongensis & 5383 & 3444 & 7788 & 8466 & 0.9 & 0.6 & 1.3 & 1.4 \\
S. apelatala & 3126 & 8109 & 11,934 & 15,016 & 0.5 & 1.3 & 2.0 & 2.5 \\
Total & 602,646 & 604,267 & 594,062 & 597,779 & 100 & 100 & 100 & 100 \\
\hline
\end{tabular}

Table 3. Analysis of mangrove species composition dynamics of the Sundarbans (1977-2015).

\begin{tabular}{|c|c|c|c|c|c|c|c|c|c|}
\hline \multirow{2}{*}{$\begin{array}{c}\text { Mangrove } \\
\text { Species }\end{array}$} & \multicolumn{4}{|c|}{ Change in Area (in Hectares) } & \multicolumn{4}{|c|}{ Percentage Change } & \multirow{2}{*}{$\begin{array}{c}\begin{array}{c}\text { Annual Rate } \\
\text { of Change } \\
\text { (in Hectares) }\end{array} \\
1977 \text { to } 2015\end{array}$} \\
\hline & $\begin{array}{c}1977 \text { to } \\
1989\end{array}$ & $\begin{array}{c}1989 \text { to } \\
2000\end{array}$ & $\begin{array}{c}2000 \text { to } \\
2015\end{array}$ & $\begin{array}{c}1977 \text { to } \\
2015\end{array}$ & $\begin{array}{c}1977 \text { to } \\
1989\end{array}$ & $\begin{array}{c}1989 \text { to } \\
2000\end{array}$ & $\begin{array}{c}2000 \text { to } \\
2015\end{array}$ & $\begin{array}{c}1977 \text { to } \\
2015\end{array}$ & \\
\hline H. fomes & -3835 & -3372 & $-14,822$ & $-22,029$ & -1.7 & -1.5 & -6.9 & -9.9 & -580 \\
\hline E. agallocha & -4970 & $-17,267$ & +2317 & $-19,920$ & -2.5 & -8.8 & +1.3 & -9.9 & -524 \\
\hline C. decandra & +7381 & +2266 & $+12,461$ & $+22,108$ & +4.3 & +1.3 & +6.9 & +12.9 & +582 \\
\hline X. mekongensis & -1939 & +4344 & +678 & +3083 & -36.0 & +126.1 & +8.7 & +57.3 & +81 \\
\hline S. apelatala & +4984 & +3825 & +3082 & $+11,890$ & +159.4 & +47.2 & +25.8 & +380.4 & +313 \\
\hline
\end{tabular}

Note: $(-)$ sign represents decreasing rate and (+) sign represents increasing rate.

Table 4. Mangrove cover change matrix of the Sundarbans between 1977 and 2015 (percentage).

\begin{tabular}{ccccccc}
\hline \multirow{2}{*}{ Class } & \multicolumn{5}{c}{$\mathbf{1 9 7 7}$} \\
\cline { 3 - 6 } & H. fomes & E. agallocha & C. decandra & S. apelatala & X. mekongensis \\
\hline \multirow{2}{*}{2015} & H. fomes & 81.1 & 7.4 & 2.3 & 10.0 & 0.2 \\
& E. agallocha & 16.2 & 48.7 & 26.1 & 20.1 & 16.3 \\
& C. decandra & 1.6 & 41.2 & 66.4 & 7.0 & 13.6 \\
& S. apelatala & 1.0 & 1.9 & 3.8 & 60.9 & 0.9 \\
& X. mekongensis & 0.01 & 0.9 & 1.4 & 2.0 & 69.1 \\
\hline
\end{tabular}



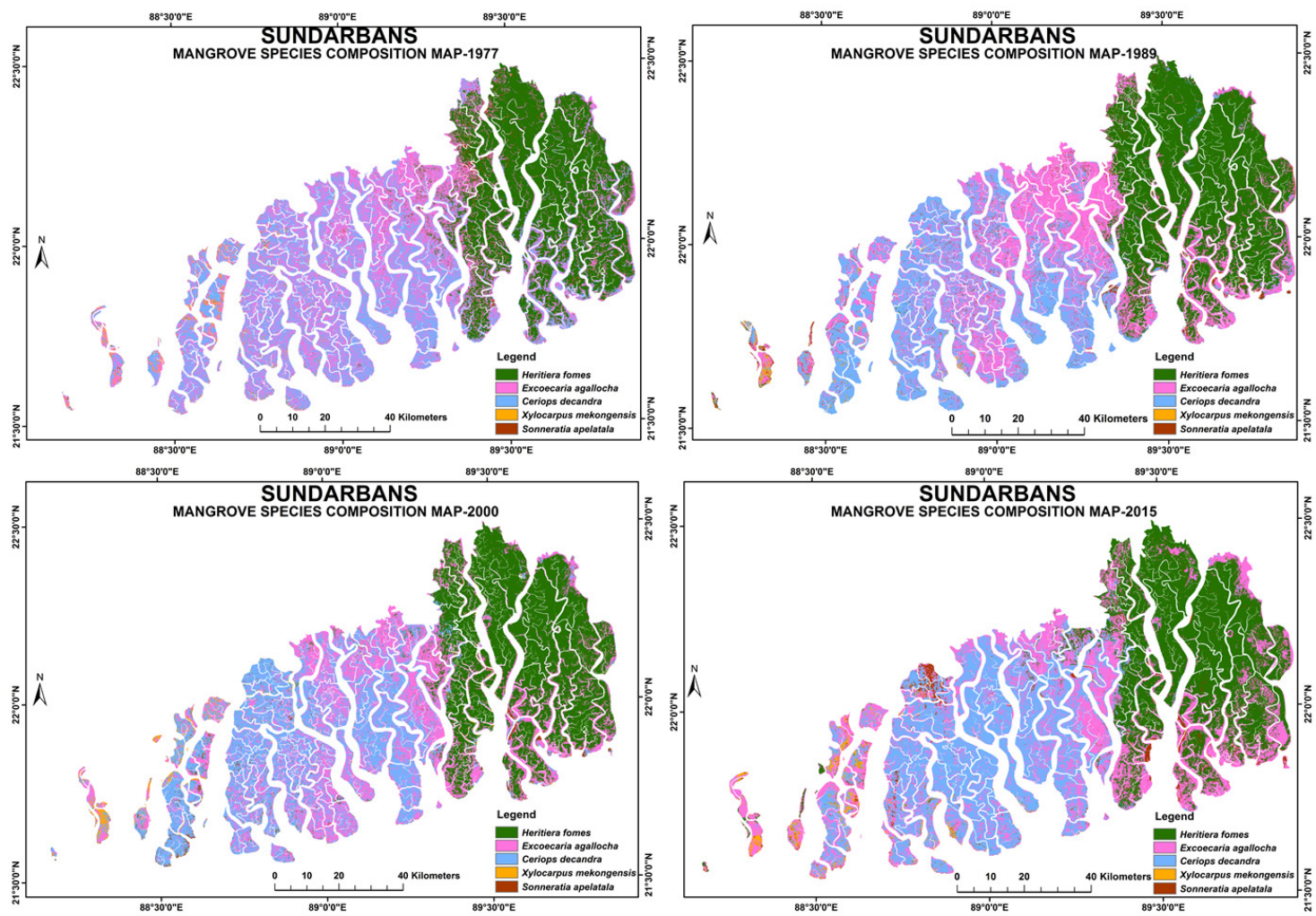

Figure 4. Mangrove species composition map of the Sundarbans mangrove forest.
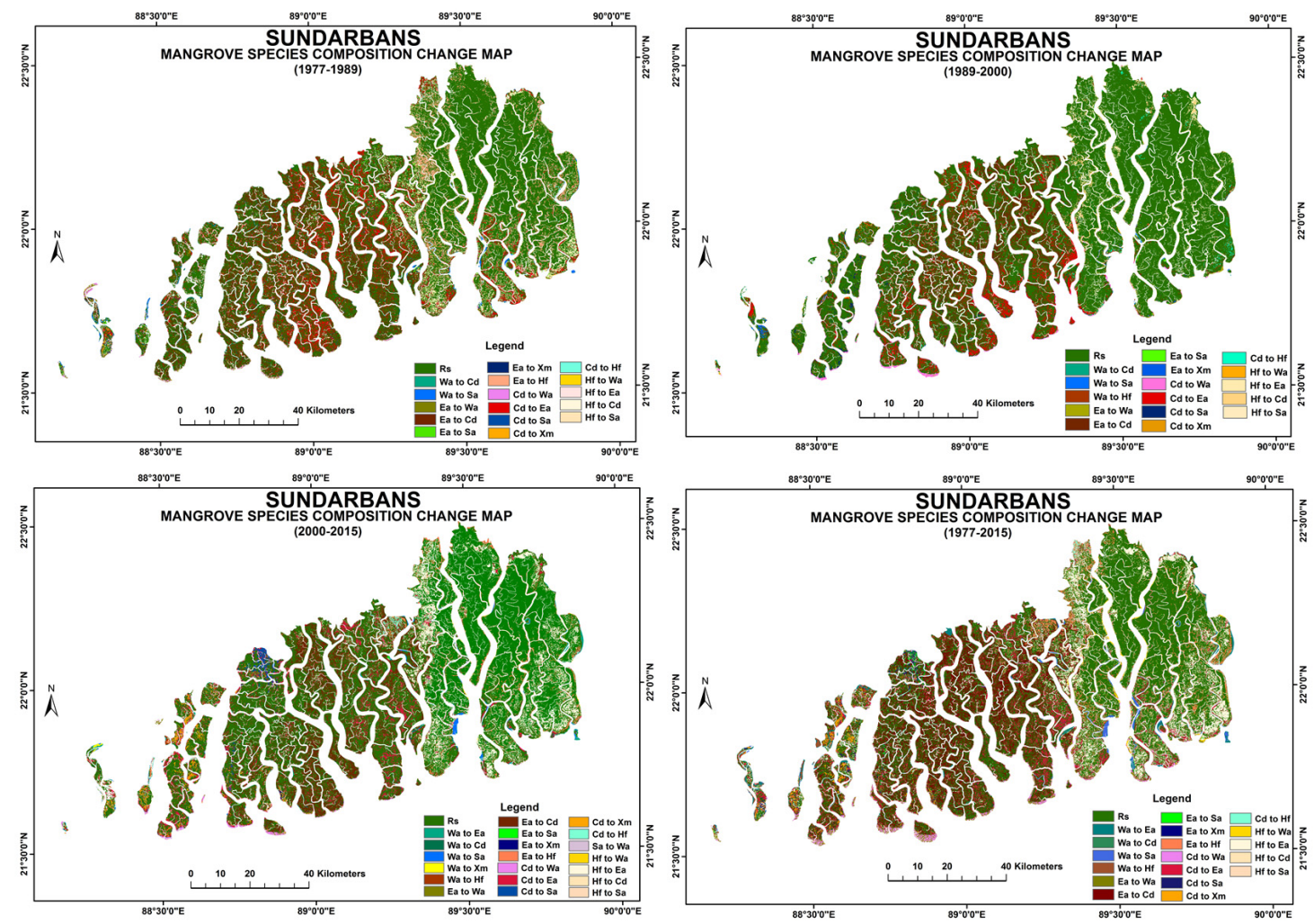

Figure 5. Mangrove species composition change map of the Sundarbans mangrove forest (Rs = Remained the same, $\mathrm{Wa}=$ Water, $\mathrm{Ea}=$ Excoecaria agallocha, $\mathrm{Cd}=$ Ceriops decandra, $\mathrm{Sa}=$ Sonneratia apelatala, $\mathrm{Xm}=$ Xylocarpus mekongensis, $\mathrm{Hf}=$ Heritiera fomes) . 


\section{Discussion}

The results reveal that the extent of the Sundarbans mangrove forest has changed little in net area (approximately $0.81 \%$ ) despite having one of the highest population densities in the world in its immediate vicinity, but the forest health, structure and species composition have changed substantially in the last 38 years (1977-2015). This finding is consistent with other recent studies at the local level $[33,34,37,62]$.

The Sundarbans mangrove ecosystem is constantly changing across both temporal and spatial scales due to different natural and anthropogenic forces. Mangroves in other parts of the world are also experiencing similar changes due to similar types of forces. Global mangrove losses because of anthropogenic factors have increased substantially during the last three decades. Clear-cutting, land-use change, hydrological alterations, chemical spills and climate change are creating immense pressure on the existing mangrove forests worldwide. In the future, sea-level rise could be the greatest threat to mangrove ecosystems. According to the predictions suggested by the IPCC [63], $30 \%-40 \%$ of coastal wetlands as well as $100 \%$ of the global mangroves [64] could be lost in the next 100 years if the present rate of loss continues. As a result, important ecosystem services and goods provided by mangroves could be diminished or lost forever [63]. The findings of this study are expected to serve as a baseline to develop adaptive management strategies in anticipation of sea-level rise, set conservation priorities, monitor deforestation and forest degradation, improve terrestrial carbon accounting and quantify the role of mangrove forests in saving lives and property from natural disasters such as cyclones and tsunamis.

Describing the reasons for changes in species composition of the Sundarbans mangrove ecosystem over time is an extremely complex task because of its multidimensional nature in terms of ecology and economy. The Total Economic Value (TEV) highlights the multidimensional nature of the economic value of this ecosystem, which includes direct-use values such as food, medicines, and forest products, and indirect-use values such as habitat provision, nutrient recycling, water purification, carbon absorption, flood control and protection against cyclones and water surges. This importance of ecology and economy has already been reported $[14-17,19,24]$. Due to this ecological and economic importance, the Sundarbans is faced with increased pressure from local demand, but the nature of pressure is not uniform, either spatially or temporally. As a consequence, it is difficult to specify the driving forces of change and their proportion of influence over time; therefore, such forces were only qualitatively identified.

Analysis of mangrove species composition change in the Sundarbans mangrove forest shows that the areas under H. fomes and E. agallocha decreased during the study period. In contrast, the area under $C$. decandra, X. mekongensis and S. apelatala increased during the last 38 years. Different natural forces, such as cyclones, coastal erosion and accretion, naturally shifting hydrology, changing climate and sea level rise, have adverse effects on the Sundarbans mangrove forest (see Table 5 for the underlying mechanism of the impact of these natural forces). Increasing water salinity and immersed areas in coastal regions as a result of changing climate are set to affect the ecosystem of the Sundarbans mangrove forest. As a result, a wide range of impacts is anticipated in the Sundarbans. The availability of freshwater, water salinity, variation in drainage and the siltation process have a substantial influence on the spatial distribution of mangrove species in the Sundarbans [16]. Chaffey and co-authors [29] divided the Sundarbans mangrove forest into three ecological zones: (a) freshwater or oligohaline (north-eastern part, the dominant species is H. fomes); (b) moderately saline or mesohaline (middle southern part, the dominant species is E. agallocha) and (c) saline or polyhaline (southern part, the dominant species is C. decandra). During the last four decades, salinity has increased in the Sundarbans region. For instance, Islam and Gnauck [65] analysed the time series salinity data of the Passur River-Mongla point and reported that the salinity rate was $<10 \mathrm{ds} / \mathrm{m}$ in 1968 during the dry season, while in the same season in 2003, the highest salinity rate was $25 \mathrm{ds} / \mathrm{m}$ (see Figure 6 for details). Therefore, a large variation has been observed in salinity levels during the time period of 35 years. As a consequence of increasing salinity in the Sundarbans, mesohaline areas are transforming 
into polyhaline areas, especially in the western and south-western parts of the forest. On the other hand, oligohaline areas are transforming into mesohaline areas. Karim [66] found approximately $60 \%$ of the western part was polyhaline, about $35 \%$ was mesohaline and less than $5 \%$ was oligohaline. Following the transformation of the ecological zones, new tree species that are more adapted to habitats with more salinity have encroached the areas that were previously occupied by other species.

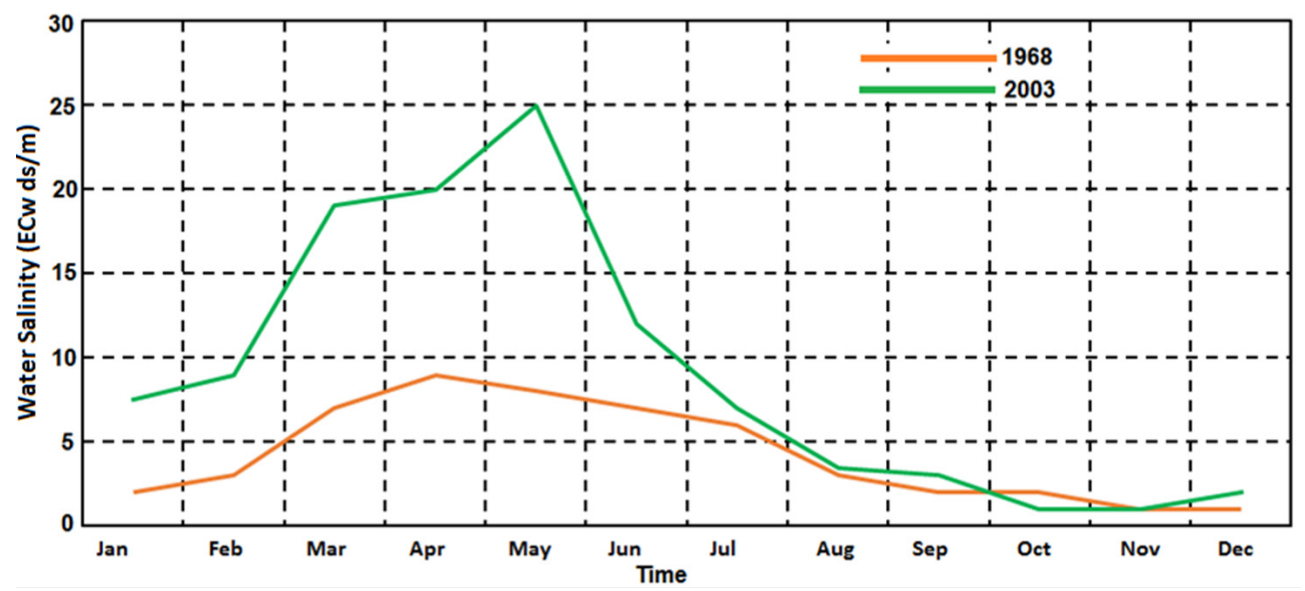

Figure 6. Water salinity density at the Passur-Mongla River site (1968-2003). (Based on data from Islam and Gnauck (65)).

H. fomes is distributed mainly in the Sundarbans eastern region, which is subject to more frequent flooding and less water salinity influence. H. fomes is the most commercially valuable species in the Sundarbans, contributing $60 \%$ of the forest's merchantable timber $[15,67]$; however, it decreased by $9.9 \%$ in 2015 relative to 1977 . A substantial change (6.9\% decrease) was observed between the time period 2000 and 2015. A phenomenon commonly called die-back disease that is highly related to the level of salinity affects the $H$. fomes trees, and this is one of the major causes of deteriorating forest cover of $H$. fomes species.

Table 5. Mechanism underlying the impact of different natural forces on mangrove forests.

\begin{tabular}{|c|c|c|}
\hline Natural Force & How It Works & Impact \\
\hline Cyclone & $\begin{array}{l}\text { 1. High speed wind } \\
\text { 2. Flooding }\end{array}$ & $\begin{array}{ll}\text { 1. } & \text { Tree falling } \\
\text { 2. } & \text { Salinity increase } \\
\text { 3. } & \text { Soil erosion } \\
\end{array}$ \\
\hline Climate change & $\begin{array}{l}\text { 1. Global warming } \\
\text { 2. Sea level rise } \\
\text { 3. Changes in rainfall pattern in the catchment }\end{array}$ & $\begin{array}{ll}\text { 1. } & \text { Coastal inundation for longer periods } \\
\text { 2. } & \text { Salinity increase } \\
\text { 3. } & \text { Changes in germination rates } \\
\text { 4. } & \text { Changes in flowering time } \\
\end{array}$ \\
\hline Coastal accretion & $\begin{array}{l}\text { Fine sediment particles are carried in as suspension } \\
\text { from upstream and by coastal waters. Sediments } \\
\text { from coastal water settle in the forest during slack } \\
\text { high tide as the friction caused by the high } \\
\text { mangrove vegetation density slows tidal currents, } \\
\text { whereas upstream sediments get trapped by the } \\
\text { plant litter on the soil surface [68] }\end{array}$ & $\begin{array}{l}\text { 1. Settlement of new mudflat } \\
\text { 2. Germination of mangrove species in } \\
\text { newly created mudflats } \\
\text { 3. Area under mangrove increases }\end{array}$ \\
\hline Coastal erosion & $\begin{array}{l}\text { 1. Storms and other high water events washout } \\
\text { the sediments }\end{array}$ & $\begin{array}{ll}\text { 1. } & \text { Loss of land } \\
\text { 2. } & \text { Tree falling }\end{array}$ \\
\hline
\end{tabular}

Die-back disease started to spread over a large scale since 1980 [69], bringing about the observed changes in $H$. fomes, which has also been confirmed by our study. E. agallocha is the dominant woody species in the Sundarbans southern region, where there is evidently the greatest seasonal variation in salinity levels and possibly represents an area of relatively longer duration of moderate salinity. 
It is often mixed with $H$. fomes, which it is able to displace under circumstances such as artificially opened canopies where $H$. fomes does not regenerate as effectively. It is also frequently associated with a dense understory of $C$. decandra [16]. It is also interspersed with $H$. fomes and $C$. decandra in Sundarbans eastern and western regions, respectively. E. agallocha decreased by $9.9 \%$ in 2015 with respect to 1977 in the Sundarbans. In the first two intervals, the area under E. agallocha decreased, but the results suggest the situation was different for the 2000 to 2015 time period, where the area under E. agallocha actually increased, and this finding is also consistent with the reported result of Giri and co-authors [39] for the Indian Sundarbans. Following the declaration of the Sundarbans as a world heritage site, the Forest Department imposed a ban on the felling of E. agallocha trees in 1999, which was the main raw material for the Khulna newsprint paper mill that was established in 1959, and this can be considered as one of the crucial factors for the observed changes in E. agallocha coverage, which increased during the study period. C. decandra, a species that is more adapted to habitats with more salinity and which is located in the Sundarbans western region and in more saline places in the Sundarbans eastern and southern regions, increased by $12.9 \%$ during the study period. Increasing salinity has played an important role in bringing the observed changes in C. decandra coverage and in species composition in the Sundarbans, especially in the western and southern part of the forest where C. decandra encroached the areas previously occupied by other species. S. apelatala, an indicator species for newly accreted mud banks and an important species for wildlife, increased by $380.4 \%$ in 2015 with respect to 1977. Coastal dynamics, land reclamation polices and afforestation programs of the Forest Department have played an influential role in the increment of $S$. apelatala trees in the Sundarbans. S. apelatala is distributed mainly in the south-eastern part (Sarankhola and Chandpai range) of the forest, the northern part of the Khulna range and the north-western part of the forest; X. mekongensis is distributed mainly in the western part of the forest (Indian portion) and some parts of the Khulna range. From 1977 to 2015, the area under X. mekongensis species increased by $57.3 \%$ in the Sundarbans.

Coastal dynamics (erosion and accretion) are one of the crucial factors that have played an important role in bringing about the changes in the Sundarbans mangrove forest. Geomorphology of the Sundarbans area is extremely dynamic due to the apparent acceleration of erosion and accretion [49]. Our results, based on the changes in species composition and habitats, suggest that erosion is more active than accretion in the study area.

Along the Sundarbans coastline, retreat is evident everywhere, but large areas of erosion have been observed in the south and south-western parts (sites A, B and C in Figure 7) during the study period. In contrast, small islands are currently forming at the mouth of Baleshwar, Bhanba and Haringhata Rivers (sites D, E and F in Figure 7). The highest coastal retreat was observed around the Bhangadhuni Island (site B) with an average annual rate of $66 \mathrm{~m} /$ year between 1977 and 2015, and this finding is consistent with the reported result of Rahman and co-authors [70]. Different anthropogenic and natural forces play a detrimental role in increasing the coastal retreat of the Sundarbans coast, which increases the vulnerability of mangroves [3]. On the other hand, accretion of the Sundarbans coast plays an active role in the increment of the areal extent of mangrove forests and also in mangrove species composition dynamics. Most of the newly accreted islands are afforested by salt-tolerant S. apelatala trees in the preliminary stage, and this helps advance the sedimentation process. This is one of the major influential factors behind the observed changes in the area under $S$. apelatala trees in the Sundarbans mangrove forests during the study period. 


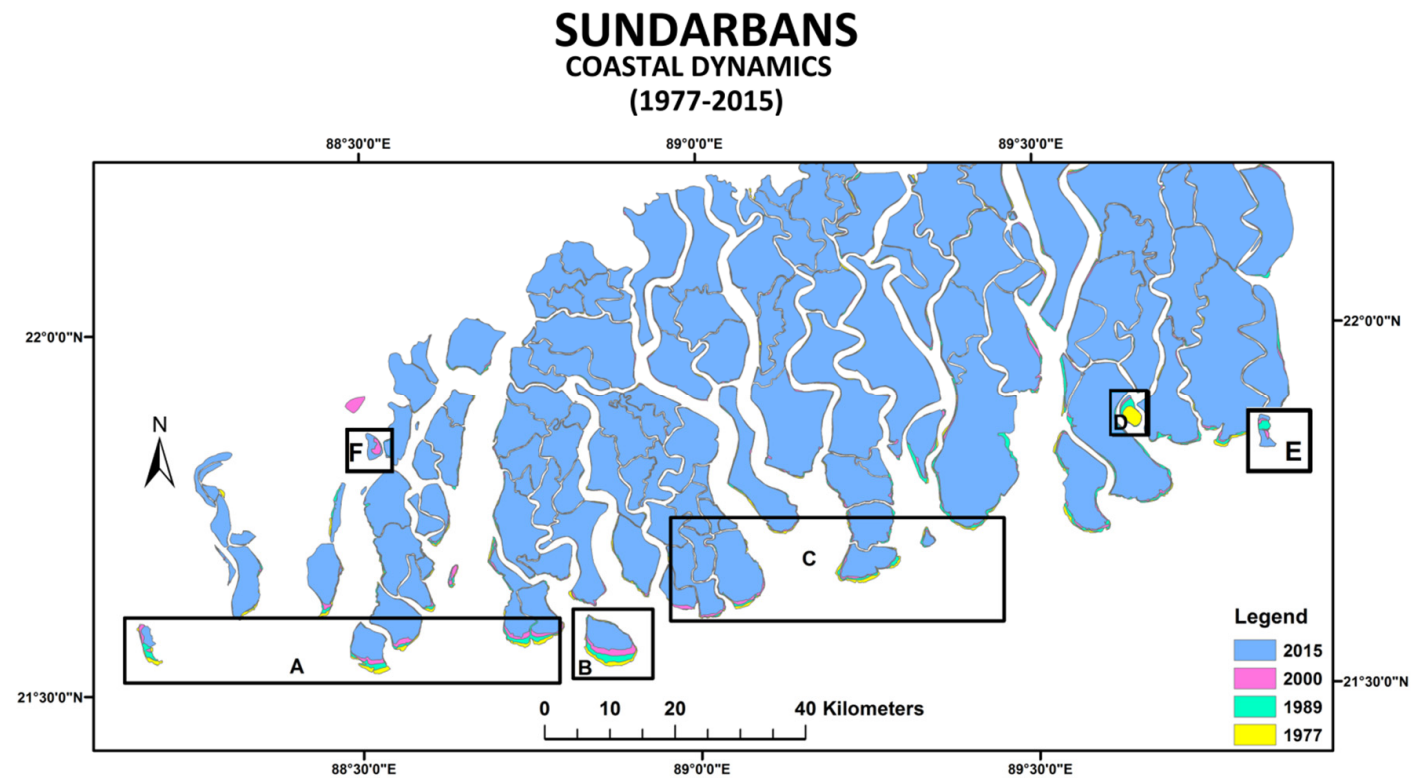

Figure 7. Effects of coastal dynamics (coastal erosion and accretion) showing the change between 1977 and 2015 in the Sundarbans coast.

Increasing population in the immediate vicinity of the Sundarbans has greatly increased the rate of exploitation of this forest, leading to serious degradation of the forest. As a result of the wide gap between the demand and supply of wood and almost permanent unemployment in the neighboring areas, there is an increasing dependence on the collection of wood from the forests for subsistence [68]. Due to over-exploitation of timber, both legally and illegally, large woody trees like E. agallocha and $H$. fomes are disappearing at an alarming rate, and this affects the biodiversity of the forest. In addition, other anthropogenic activities, such as oil spills and fire for clearing forest for cultivation, put this mangrove forest under tremendous pressure in terms of sustainability.

To evaluate the accuracy of image classification, an overall classification accuracy and kappa index were calculated for each image. The classified image of 2015 resulted in the highest overall accuracy and kappa coefficient ( $89 \%$ and 0.87 ) followed by the classified images of 1989 ( $84 \%$ and 0.75 ), $2000(79 \%$ and 0.73) and 1977 (72\% and 0.63). It is notable that the MSS 1977 and ETM+ 2000 images resulted in relatively lower overall accuracies and kappa coefficient. This could be due to the fact that we developed training samples for them using the reference data that were not closely matched with the image dates, although we undertook additional processing to develop training samples for them due to the unavailability of reference data for these periods. Despite obtaining relatively low overall accuracies and kappa coefficient, the result is still acceptable considering the unavailability of reference data for older datasets and the coarse resolution of the MSS 1977 imagery.

\section{Conclusions}

The importance of the Sundarbans mangrove forest extends from the local to global scale, where different stakeholders' objectives attempt to decide its future. Due to unplanned and illegal anthropogenic activities, climate change and extreme weather events, this important mangrove ecosystem has been adversely affected during the last 250 years. In this situation, regular information on mangrove species composition, their spatial distribution and the changes that are taking place over time is very important for a thorough understanding of mangrove biodiversity and mangrove management in a sustainable manner. Emphasis on preparing databases related to mangrove species composition and the species-level dynamics of the Sundarbans mangrove forest for managing the entire ecosystem may help to sustain this valuable resource well into the future. To do this, simple, time saving, efficient and low cost methods are required. In this study, we used conventional 
medium-resolution Landsat data and conventional classification and change detection methods to identify mangrove species composition and detect species level changes over time. Our results show the potential of producing relatively accurate mangrove species composition and change detection databases using Landsat images.

Over the study period, H. fomes and E. agallocha both decreased by $9.9 \%$ in the Sundarbans. In contrast, C. decandra, S. apelatala and X. mekongensis increased by $12.9 \%, 380.4 \%$ and $57.3 \%$, respectively. Different natural and anthropogenic influences, such as over-exploitation of timber and pollution, coastal erosion and accretion, increasing salinity, die-back disease and changing climate, have played an important role in bringing about the observed changes in the mangrove species composition in the Sundarbans.

Continuous monitoring is important for developing a better management plan for the Sundarbans. In future, the results obtained in this study could provide invaluable quantitative information for better and sustainable management of the Sundarbans mangrove ecosystem. This result can also be shared with forest management planners, relevant stakeholders and policy makers for use in decision-making on such issues as forest management planning and identification of low cost methods, which could be used in the context of integrated forest management.

Author Contributions: M.K.G., L.K. and C.R. conceived and designed the experiments; M.K.G. performed the experiments and analyzed the data; M.K.G. wrote the paper and L.K. edited the paper.

Conflicts of Interest: The authors declare no conflict of interest.

\section{References}

1. Giri, C.; Ochieng, E.; Tieszen, L.L.; Zhu, Z.; Singh, A.; Loveland, T.; Duke, N. Status and distribution of mangrove forests of the world using earth observation satellite data. Glob. Ecol. Biogeogr. 2011, 20, 154-159. [CrossRef]

2. Marchio, D.A.; Savarese, M.; Bovard, B.; Mitsch, W.J. Carbon Sequestration and Sedimentation in Mangrove Swamps Influenced by Hydrogeomorphic Conditions and Urbanization in Southwest Florida. Forests 2016, 7, 116. [CrossRef]

3. Cornforth, W.A.; Fatoyinbo, T.E.; Freemantle, T.P.; Pettorelli, N. Advanced land observing satellite phased array type L-band SAR (ALOS PALSAR) to inform the conservation of mangroves: Sundarbans as a case study. Remote Sens. 2013, 5, 224-237. [CrossRef]

4. Alongi, D.M. Present state and future of the world's mangrove forests. Environ. Conserv. 2002, 29, 331-349. [CrossRef]

5. Giri, C.; Muhlhausen, J. Mangrove forest distributions and dynamics in Madagascar (1975-2005). Sensors 2008, 8, 2104-2117. [CrossRef] [PubMed]

6. Valiela, I.; Bowen, J.L.; York, J.K. Mangrove Forests: One of the World's Threatened Major Tropical Environments. Bioscience 2001, 51, 807-815. [CrossRef]

7. Myint, S.W.; Giri, C.; Wang, L.; Zhu, Z.; Gillette, S.C. Identifying mangrove species and their surrounding land use and land cover classes using an object-oriented approach with a lacunarity spatial measure. GISci. Remote Sens. 2008, 45, 188-208. [CrossRef]

8. Asbridge, E.; Lucas, R.; Ticehurst, C.; Bunting, P. Mangrove response to environmental change in Australia's Gulf of Carpentaria. Ecol. Evol. 2016, 6, 3523-3539. [CrossRef] [PubMed]

9. Ghosh, A.; Schmidt, S.; Fickert, T.; Nüsser, M. The Indian Sundarban mangrove forests: History, utilization, conservation strategies and local perception. Diversity 2015, 7, 149-169. [CrossRef]

10. Spalding, M.; Kainuma, M.; Collins, L. World Atlas of Mangroves; Earthscan: London, UK, 2010; p. 319.

11. Biswas, S.R.; Choudhury, J.K.; Nishat, A.; Rahman, M.M. Do invasive plants threaten the Sundarbans mangrove forest of Bangladesh? For. Ecol. Manag. 2007, 245, 1-9. [CrossRef]

12. Hussain, Z.; Acharya, G. Mangroves of the Sundarbans. Volume 2: Bangladesh; International Union for Conservation of Nature AND Natural Resources (IUCN): Gland, Switzerland, 1994; Volume 2, p. 257.

13. Rahman, M.; Asaduzzaman, M. Ecology of Sundarban, Bangladesh. J. Sci. Found. 2013, 8, 35-47. [CrossRef]

14. Bose, S. Role of Indian Sunderban Mangroves in Mitigating Climate Impacts: An Appraisal; IOP Conference Series: Earth and Environmental Science; IOP Publishing: Copenhagen, Denmark, 2009. 
15. Giri, C.; Pengra, B.; Zhu, Z.; Singh, A.; Tieszen, L.L. Monitoring mangrove forest dynamics of the Sundarbans in Bangladesh and India using multi-temporal satellite data from 1973 to 2000. Estuar. Coast. Shelf Sci. 2007, 73, 91-100. [CrossRef]

16. Rahman, L.M. The Sundarbans: A Unique Wilderness of the World; USDA Forest Service Proceedings RMRS-P-15-VOL-2; USDA Forest Service: Ogden, UT, USA, 2000; pp. 143-148.

17. Donato, D.C.; Kauffman, J.B.; Murdiyarso, D.; Kurnianto, S.; Stidham, M.; Kanninen, M. Mangroves among the most carbon-rich forests in the tropics. Nat. Geosci. 2011, 4, 293-297. [CrossRef]

18. Rodda, S.R.; Thumaty, K.C.; Jha, C.S.; Dadhwal, V.K. Seasonal Variations of Carbon Dioxide, Water Vapor and Energy Fluxes in Tropical Indian Mangroves. Forests 2016, 7, 35. [CrossRef]

19. Islam, M.S. How Worthy is the Sundarbans Mangrove Forest? An Exploratory Study. Environ. Nat. Resour. 2016, 14, 17-25.

20. Wells, S.; Ravilious, C. In the Front Line: Shoreline Protection and Other Ecosystem Services from Mangroves and Coral Reefs; UNEP/Earthprint: Cambridge, UK, 2006.

21. Iftekhar, M. An overview of mangrove management strategies in three South Asian countries: Bangladesh, India and Sri Lanka. Int. For. Rev. 2008, 10, 38-51. [CrossRef]

22. Leong, L. Economic Valuation of the Mangrove Forests in Kuala Selangor, Malaysia. Master's Thesis, University of Malaya, Kuala Lumpur, Malaysia, 1999.

23. Cabrera, M.A.; Seijo, J.C.; Euan, J.; Pérez, E. Economic values of ecological services from a mangrove ecosystem. Intercoast Netw. 1998, 32, 1-2.

24. Costanza, R.; d'Arge, R.; De Groot, R.; Faber, S.; Grasso, M.; Hannon, B.; Limburg, K.; Naeem, S.; O’neill, R.V.; Paruelo, J.; et al. The value of the world's ecosystem services and natural capital. Nature 1997, 387, 253-260. [CrossRef]

25. Syed, M.A.; Hussin, Y.A.; Weir, M. Detecting fragmented mangroves in the Sundarbans, Bangladesh using optical and radar satellite images. In Proceedings of the 22nd Asian Conference on Remote Sensing, Singapore, 5-9 November 2001; Volume 5, p. 9.

26. Danda, A.A. Surviving in the Sundarbans: Threats and Responses: An Analytical Description of Life in an Indian Riparian Commons. Ph.D. Thesis, University of Twente, Enschede, The Netherland, 2007; pp. 14-23.

27. Iftekhar, M. Forestry in Bangladesh: An overview. J. For. 2006, 104, 148-153.

28. Chaudhuri, A.B.; Choudhury, A. Mangroves of the Sundarbans. Volume 1: India; International Union for Conservation of Nature and Natural Resources (IUCN): Bangkok, Thailand, 1994.

29. Chaffey, D.R.; Miller, F.; Sandom, J. A FOREST INVENTORY of the Sundarbans, Bangladesh; Land Resources Development Centre: Surrey, UK, 1985.

30. Iftekhar, M.; Saenger, P. Vegetation dynamics in the Bangladesh Sundarbans mangroves: A review of forest inventories. Wetl. Ecol. Manag. 2008, 16, 291-312. [CrossRef]

31. Wang, L.; Sousa, W.P.; Gong, P.; Biging, G.S. Comparison of IKONOS and QuickBird images for mapping mangrove species on the Caribbean coast of Panama. Remote Sens. Environ. 2004, 91, 432-440. [CrossRef]

32. Giri, C.; Zhu, Z.; Tieszen, L.; Singh, A.; Gillette, S.; Kelmelis, J. Mangrove forest distributions and dynamics (1975-2005) of the tsunami-affected region of Asia. J. Biogeogr. 2008, 35, 519-528. [CrossRef]

33. Blasco, F.; Aizpuru, M.; Gers, C. Depletion of the mangroves of Continental Asia. Wetl. Ecol. Manag. 2001, 9, 255-266. [CrossRef]

34. Dwivedi, R.; Rao, B.; Bhattacharya, S. Mapping wetlands of the Sundaban Delta and it's environs using ERS-1 SAR data. Int. J. Remote Sens. 1999, 20, 2235-2247. [CrossRef]

35. Emch, M.; Peterson, M. Mangrove forest cover change in the Bangladesh Sundarbans from 1989-2000: A remote sensing approach. Geocarto Int. 2006, 21, 5-12. [CrossRef]

36. Iftekhar, M.; Islam, M. Managing mangroves in Bangladesh: A strategy analysis. J. Coast. Conserv. 2004, 10, 139-146. [CrossRef]

37. Islam, M.J.; Alam, M.S.; Elahi, K.M. Remote sensing for change detection in the Sunderbands, Bangladesh. Geocarto Int. 1997, 12, 91-100. [CrossRef]

38. Islam, M.T.; Broström, G.; Christensen, K.; Drivdal, M.; Weber, J.; Shendryk, I.; Alwmark, C. Vegetation changes of Sundarbans based on Landsat Imagery analysis between 1975 and 2006. Landsc. Environ. 2014, 8, 1-9. 
39. Giri, S.; Mukhopadhyay, A.; Hazra, S.; Mukherjee, S.; Roy, D.; Ghosh, S.; Mitra, D. A study on abundance and distribution of mangrove species in Indian Sundarban using remote sensing technique. J. Coast. Conserv. 2014, 18, 359-367. [CrossRef]

40. Choudhury, K.; Waliuzzaman, M.; Nishat, A.; Reza, A.A. The Bangladesh Sundarbans: A Photoreal Sojourn; IUCN Bangladesh Country Office, IUCN the World Conservation Union: Dhaka, Bangladesh, 2001.

41. Siddiqi, N. Mangrove Forestry in Bangladesh; Institute of Forestry and Environmental Sciences, University of Chittagong: Chittagong, Bangladesh, 2001.

42. Bhowmik, A.K.; Cabral, P. Cyclone Sidr Impacts on the Sundarbans Floristic Diversity. Earth Sci. Res. 2013, 2, 62. [CrossRef]

43. Duke, N.C. Mangrove floristics and biogeography. Trop. Mangrove Ecosyst. 1993, 63-100. [CrossRef]

44. Chavez, P.S. Image-based atmospheric corrections-revisited and improved. Photogramm. Eng. Remote Sens. 1996, 62, 1025-1035.

45. Rahdary, V.; Najfabdai, S.M.; Khajeddin, S. Land Use and Land Cover Change Detection of Mouteh Wildlife Refuge Using Remotely Sensed Data and Geographic Information System. World Appl. Sci. J. 2008, 3 (Suppl. 1), 113-118.

46. Chander, G.; Markham, B. Revised Landsat-5 TM radiometric calibration procedures and postcalibration dynamic ranges. IEEE Trans. Geosci. Remote Sens. 2003, 41, 2674-2677. [CrossRef]

47. Mas, J.-F. Monitoring land-cover changes: A comparison of change detection techniques. Int. J. Remote Sens. 1999, 20, 139-152. [CrossRef]

48. Coppin, P.; Jonckheere, I.; Nackaerts, K.; Muys, B.; Lambin, E. Digital change detection methods in ecosystem monitoring: A review. Int. J. Remote Sens. 2004, 25, 1565-1596. [CrossRef]

49. Ghosh, M.K.; Kumar, L.; Roy, C. Monitoring the coastline change of Hatiya Island in Bangladesh using remote sensing techniques. ISPRS J. Photogramm. Remote Sens. 2015, 101, 137-144. [CrossRef]

50. Chen, C.-F.; Son, N.-T.; Chang, N.-B.; Chen, C.-R.; Chang, L.-Y.; Valdez, M.; Aceituno, J.L. Multi-decadal mangrove forest change detection and prediction in Honduras, Central America, with Landsat imagery and a Markov chain model. Remote Sens. 2013, 5, 6408-6426. [CrossRef]

51. Foody, G.M. Thematic map comparison. Photogramm. Eng. Remote Sens. 2004, 70, 627-633. [CrossRef]

52. Foody, G.M. Harshness in image classification accuracy assessment. Int. J. Remote Sens. 2008, 29, 3137-3158. [CrossRef]

53. Sinha, P.; Kumar, L. Independent two-step thresholding of binary images in inter-annual land cover change/no-change identification. ISPRS J. Photogramm. Remote Sens. 2013, 81, 31-43. [CrossRef]

54. Sinha, P.; Kumar, L.; Reid, N. Rank-Based Methods for Selection of Landscape Metrics for Land Cover Pattern Change Detection. Remote Sens. 2016, 8, 107. [CrossRef]

55. Alqurashi, A.F.; Kumar, L.; Sinha, P. Urban Land Cover Change Modelling Using Time-Series Satellite Images: A Case Study of Urban Growth in Five Cities of Saudi Arabia. Remote Sens. 2016, 8, 838. [CrossRef]

56. Sinha, P.; Kumar, L.; Drielsma, M.; Barrett, T. Time-series effective habitat area (EHA) modeling using cost-benefit raster based technique. Ecol. Inform. 2014, 19, 16-25. [CrossRef]

57. Congalton, R.G.; Green, K. Assessing the Accuracy of Remotely Sensed Data: Principles and Practices; CRC Press: New York, NY, USA, 2008.

58. Kumar, L.; Ghosh, M.K. Land cover change detection of Hatiya Island, Bangladesh, using remote sensing techniques. J. Appl. Remote Sens. 2012, 6, 063608. [CrossRef]

59. Treygo, W.; Dean, P.B. The Environment and Development in Bangladesh: An Overview and Strategy for the Future; Canadian International Development Agency: Ottawa, ON, Canada, 1989.

60. Congalton, R.G. A review of assessing the accuracy of classifications of remotely sensed data. Remote Sens. Environ. 1991, 37, 35-46. [CrossRef]

61. Congalton, R.G.; Oderwald, R.G.; Mead, R.A. Assessing Landsat classification accuracy using discrete multivariate analysis statistical techniques. Photogramm. Eng. Remote Sens. 1983, 49, 1671-1678.

62. Nayak, S.; Bahuguna, A. Application of remote sensing data to monitor mangroves and other coastal vegetation of India. Indian J. Mar. Sci. 2001, 30, 195-213.

63. Parry, M.L. Climate Change 2007-Impacts, Adaptation and Vulnerability: Working Group II Contribution to the Fourth Assessment Report of the IPCC; Cambridge University Press: Cambridge, UK, 2007; Volume 4.

64. Duke, N.C.; Meynecke, J.-O.; Dittmann, S.; Ellison, A.M.; Anger, K.; Berger, U.; Cannicci, S.; Diele, K.; Ewel, K.C.; Field, C.D.; et al. A world without mangroves? Science 2007, 317, 41-42. [CrossRef] [PubMed] 
65. Islam, S.; Gnauck, A. Threats to the Sundarbans mangrove wetland ecosystems from transboundary water allocation in the Ganges basin: A preliminary problem analysis. Int. J. Ecol. Econ. Stat. (IJEES) 2009, 13, 64-78.

66. Karim, A. The physical environment. In Mangroves of the Sundarbans. Volume Two: Bangladesh; Hussain, Z., Acharya, G., Eds.; IUCN: Bangkok, Thailand, 1994; pp. 11-41.

67. Rahman, M. A comprehensive report on H. fomes (H. fomes) trees with particular reference to top dying in the Sundarbans. In Proceedings of the Seminar on Top Dying of H. fomes, Dhaka, Bangladesh, 11 August 1988.

68. Cahoon, D.R.; Hensel, P.F.; Spencer, T.; Reed, D.J.; McKee, K.L.; Saintilan, N. Coastal wetland vulnerability to relative sea-level rise: Wetland elevation trends and process controls. Wetl. Nat. Resour. Manag. 2006, 271-292. [CrossRef]

69. Rahman, M.M.; Rahman, M.M.; Islam, K.S. The causes of deterioration of Sundarban mangrove forest ecosystem of Bangladesh: Conservation and sustainable management issues. AACL Bioflux 2010, 3, 77-90.

70. Rahman, A.F.; Dragoni, D.; El-Masri, B. Response of the Sundarbans coastline to sea level rise and decreased sediment flow: A remote sensing assessment. Remote Sens. Environ. 2011, 115, 3121-3128. [CrossRef]

(C) 2016 by the authors; licensee MDPI, Basel, Switzerland. This article is an open access article distributed under the terms and conditions of the Creative Commons Attribution (CC-BY) license (http://creativecommons.org/licenses/by/4.0/). 